\title{
O GUARDIÃO DA VILA DE LAPINHA DA SERRA
}

THE GUARDIAN OF THE VILLAGE OF LAPINHA DA SERRA

Alexandre Romariz Sequeira

UFPA

Resumo: A partir de uma proposição artística de natureza relacional, o presente artigo trata das possíveis intersecções entre o ato de viver e o ato de criar. Interessa-me analisar a dissociação entre os limites do "sujeito empírico" e do "sujeito artista", como também o entendimento da experiência poética sob a égide de uma estética da reflexão, que não esgota seu entendimento numa simples apreensão formal, mas convida quem dela participa a desvelá-la a partir de relações associativas com suas referências de mundo.

Palavras-chave: Arte; Arte relacional; Autoficção poética.

Abstract: Based on an artistic proposition of a relational nature, this article deals with the possible intersections between the act of living and the act of creating. I am interested in analyzing the dissociation between the limits of the "empirical person" and the "artist person", as well as the understanding of the poetic experience under the aegis of an aesthetics of reflection, which does not exhaust its understanding in a simple formal apprehension but invites those who participate to reveal it from associative relationships with its world references.

keywords: Art; Relational art; Life; Poetic self-fiction. 
Muito se tem tratado sobre a importância das práticas artísticas na formação de indivíduos sejam eles crianças, jovens ou adultos; de pensar sobre as instâncias onde essas relações simbólicas se estabelecem promovendo profícuas relações entre valores éticos e estéticos. Refletir sobre essa dimensão oferece a oportunidade de ampliarmos a discussão sobre os limites cada vez mais difusos que definem os espaços onde práticas de natureza artística e de natureza formadora ou educativa se estabelecem. Pensar a Arte numa perspectiva formadora demanda, invariavelmente, a compreensão de intenções que animam o próprio existir. Explorar a intrincada rede de ramificações e conexões que sustenta e oferece coerência a um discurso de natureza artística nos solicita vislumbrar relações muitas vezes não aparentes, dúbias e complexas. É como analisar um mapa alegórico, que se configura a partir de traços de uma proposta diferenciadora, gerada pelo que falta, pelo que se perdeu e pela conexão dos restos do que poderia ter sido e que não foi a partir em enunciações pautadas por uma lógica que lança luzes, mas que também deixa zonas de sombreamento, a fim de permanecer sempre em articulação com novas relações significantes.

O presente artigo parte de uma questão que, em sua natureza, é ampla e difusa: o que seria Arte? Ou ainda onde esta questão coincide com uma questão de ordem existencial: qual o sentido da vida? Viver, segundo Friedrich Nietzsche, não é apenas adaptar-se às circunstâncias externas. A vida é antes de tudo, atividade criadora; atividade formadora. O conceito de Doutrina da Vontade Criadora, por ele apresentado, é definido como "a vontade de interpretar o mundo - vontade essa que estabelece uma intrínseca relação entre arte, vida e pensamento". Nesse sentido, "a vida enquanto eterno movimento de superação é, essencialmente, atividade criado- ra e, como tal, é alguma coisa que quer expandir sua força, crescer, gerar mais vida" (DIAS, 2011, p.34). Nessa perspectiva, os mecanismos que operam na dissociação entre os limites do viver e do criar se fazem numa zona onde forças livres e disponíveis podem tanto afirmar, quanto relativizar ou mesmo desconstruir certezas estabelecidas.

Busco aqui de ilustrar essa reflexão a partir do encontro entre duas pessoas, tendo como elo de aproximação a fotografia e o interesse particular que cada uma nutria por ela. O local do encontro é o pequeno vilarejo de Lapinha da Serra localizado na Serra do Cipó, município de Santana do Riacho, no estado de Minas Gerais. O encontro se deu ao longo dos anos de 2009 e 2010. Os dois personagens são: Rafael Oliveira de Jesus, um adolescente de 13 anos de idade nativo de Lapinha da Serra e eu, na época, mestrando do programa de Pós-Graduação em Artes da Escola de Belas Artes da UFMG. Movido pela possibilidade de conhecer novos lugares no interior do estado e, quem sabe, encontrar algo que me estimulasse a desenvolver um novo trabalho artístico, percorri pequenas estradas poeirentas que serpenteiam a Serra do Cipó até, em uma dessas empreitadas, alcançar a vila de Lapinha da Serra e lá encontrar Rafael, com quem estabeleceria uma estreita relação ao longo desses dois anos.

Meu encontro com Rafael se deu logo em meus primeiros minutos no vilarejo, enquanto procurava algum lugar onde pudesse almoçar. O garoto franzino que caminhava por uma pequena viela conduzindo alguns bois em direção ao curral, imediatamente abandonou seus afazeres e se prontificou a me levar a uma casa onde se vendia refeições. Em poucos minutos no local, compreendi que havia sido levado à sua casa, onde sua avó, complementava a renda familiar vendendo refeições à turistas - público 


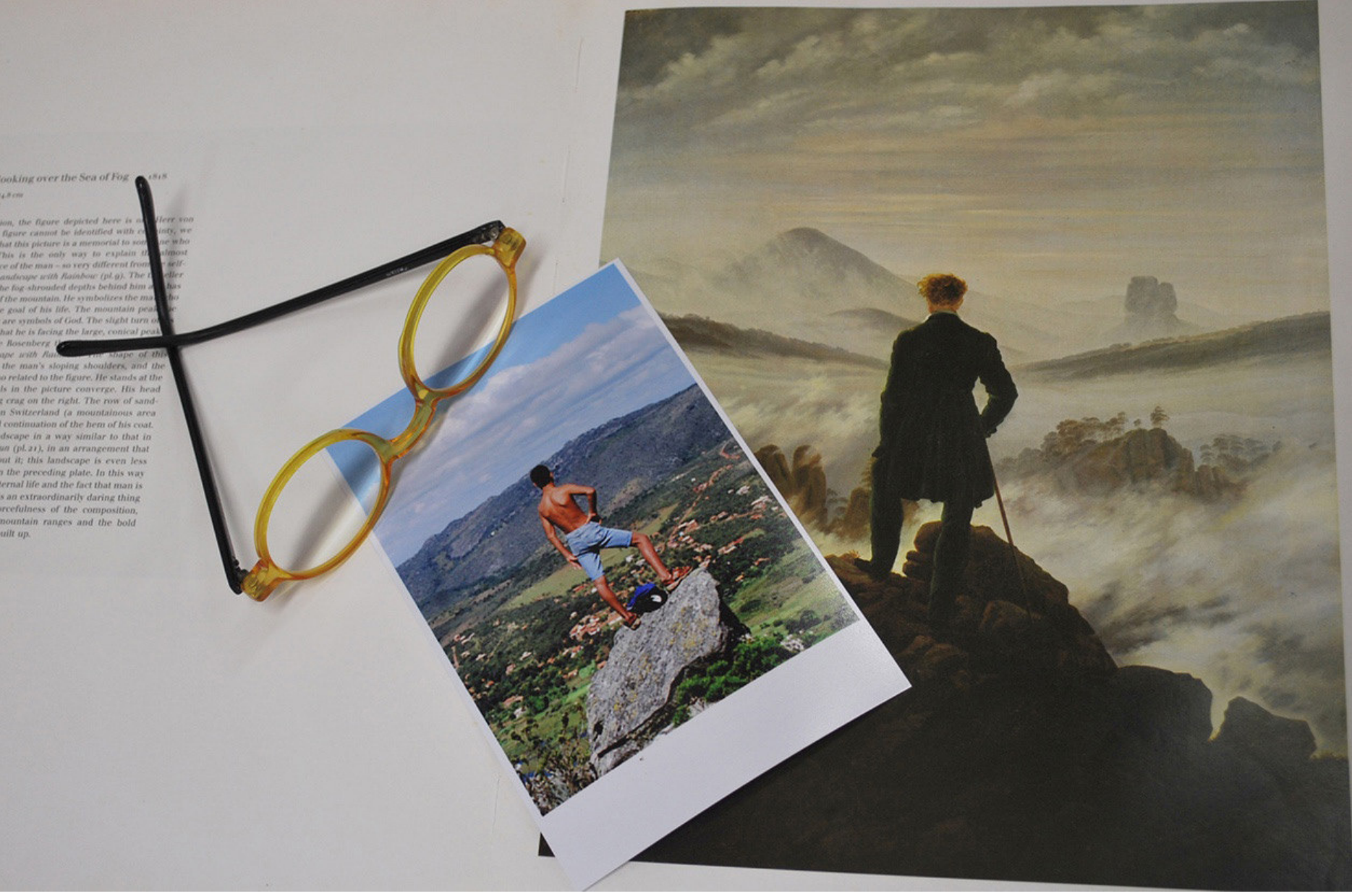

sensibilidade, Rafael apresentava-me, teatralmente, quedas d'água, flores do cerrado, ou ninhos de passarinho escondidos nos pequenos arbustos. Olhar de criança que investiga o mundo sem nenhuma pretensão, sem pressa, sem saber direito que nome dar às coisas. Ao mesmo tempo, ele me bombardeava com inúmeras perguntas sobre o meu mundo: onde morava, como era viver numa cidade grande, com que trabalhava. Os limites da vila pareciam não ser suficientes para a sede de devorar o mundo daquele garoto esperto e comunicativo. A máquina fotográfica que trazia comigo logo também foi alvo de sua curiosidade. Para minha surpresa, meu pequeno guia mostrava familiaridade com o equipamento. Dizia ter acompanhado, há algum tempo, uma equipe que produzia um documentário sobre a vila e que com eles havia Figura 2. Os dois aprendido algo sobre filmadoras e máquinas fotográficas. Rapidamente, passamos a dividir o equipamento fotográfico, alternando registros, entremeados por conversas que se estendiam pelos mais diversos assuntos. No fim da escalada, ao alcançarmos um ponto no qual se pode ter uma visão privilegiada da região, descansamos, lançando pequenas pedras montanha abaixo e calculando o tempo de sua queda. E foi ali que, de repente, fui surpreendido por uma imagem de grande significado para mim. Por alguns minutos, Rafael manteve-se sobre uma pedra no topo da montanha, com o olhar perdido no horizonte. Saltei no tempo e me reencontrei com um errante personagem que tantas vezes encarnei em minha infância ao folhear os livros viajantes. Alexandre Sequeira. 2008. Acervo do autor. 
outros moradores sobre a história que havia ouvido de meu curioso guia, tive como resposta sonoras gargalhadas. Todos foram enfáticos em afirmar que não deveria dar muita atenção às fantasias de Rafael. Segundo eles, tudo se originava no fato de que, em determinadas noites, enquanto o gado está recolhido ao curral, alguns nativos aparavam o pasto com uma máquina de cortar capim construída a partir de motor de automóvel, provocando assim um ruído estranho que ecoava pelas vielas silenciosas de Lapinha. Rafael, no entanto, preferia manter a versão do vilarejo como lugar de interesse de seres de outros planetas - opinião que fez questão de reafirmar meses depois, ao desenhar sobre um uma fotografia noturna que realizei do vilarejo a presença ameaçadora de um luminoso disco voador.

Naquela mesma tarde, ao tentarmos alcançar a praça central por uma estreita viela sem nome e cercada de mato, fui aconselhado por Rafael a correr sem parar e não olhar para trás. A princípio pensei que se tratava de uma ameaça eminente, talvez de um cão de alguma casa das redondezas. Ao alcançarmos a praça, exausto, pedi explicações à Rafael e fui por ele informado que ali, naquele caminho, havia uma grande mangueira onde, segundo ele, costumava aparecer a "Mulher do pé de manga", um dos muitos personagens que povoavam o imaginário de Rafael. Exaustos e com o coração em sobressalto diante dessa última e inesperada surpresa de nosso passeio, chegamos, por fim, à padaria local, onde fizemos um lanche e nos despedimos, seguindo cada um para sua casa, com o compromisso de nos encontrarmos no dia seguinte para nos despedirmos. Na manhã seguinte, teria que voltar para meus afazeres na cidade grande.

Minha segunda ida a Lapinha da Serra coincidiu com a semana de aniversário de Rafael. Resolvi presenteá-lo com uma pequena máquina fotográfica. Sabia do encanto que tinha por tais equipamentos e do quão fascinante seria, para mim, conhecer mais sobre a vida da vila a partir de seu olhar desinteressado. A caixa do presente foi rapidamente destruída e enorme foi a satisfação de Rafael ao constatar o seu conteúdo. Rapidamente a máquina foi analisada por ele e, após uma breve orientação quanto à colocação das pilhas, fui convidado a acompanhá-lo numa primeira atividade de campo. Começamos, a partir de então, a estreitar nossos laços afetivos, tendo a fotografia como elemento agregador. Nossas excursões pela vila, campo ou montanha passaram a ser, a partir de então, mais silenciosas. As imagens que capturávamos com nossas máquinas e mostrávamos um para o outro substituíam, muitas vezes, as palavras. Esses significados compartilhados eram a liga, o amálgama que nos unia cada vez mais. Uma relação dialógica num plano tácito, que pressupunha a possibilidade e a aceitação de infinitos pontos de vista. Em nossos diálogos imagéticos, não jogamos um contra o outro, mas sim um com o outro. Nossas imagens fotográficas, peças desse imbricado jogo de quebra-cabeça, surgiam em profusão, tantas quantas coubessem nos cartões de memória, menos como registros documentais e mais como rastros, possibilidades de entendimento. Não tentávamos mudar nada, mas apenas estar atentos a tudo. Nesse jogo, ambos vencíamos. Nada parecia ser capaz de interferir em nosso plano de convívio, por serem exclusivamente nossos os processos com que conduzíamos esses momentos. Nem percebíamos as horas passarem, em nosso passatempo de olhar para as coisas através do visor das máquinas fotográficas, em forma de visualizações ocasionais, vindas em instantes dispersos, fragmentos substanciosos - ora nos proporcionando um conhecimento literal, ora nos indicando peripécias -, mas que, aproveitados por nossas 
mentes elaboradoras, tornavam-se válidas para o enredo que construíamos a quatro mãos. Essas parcelas de um mesmo argumento, surgidas sem ordem temporal, agrupavam-se em nós, cada

uma em seu verdadeiro lugar, de maneira a tramar, com limpidez, uma nova lógica para os acontecimentos que juntos experimentávamos. Se nesse devaneio abríamos mão das palavras, deixando que sobre nós pairasse o silêncio, é porque as imagens amoldavam-se melhor ao nosso espírito, buscando ajustar-se, em todas as digressões que os olhos empreendiam, numa ordem que, em certos casos, não correspondia à realidade original, mas autenticava uma série de outras ficções idealizadas. Mesmo o que para alguns se constitui erro ou falta de domínio técnico no instante do registro, convertia-se, ali, em documento fiel do acaso e da errância. Em virtude desse desvio favorável, as imagens desprendiam-se de qualquer rigor ou compromisso formal, pousando e repousando nos pensamentos que elas mesmas sugeriam, repletas de formas inéditas.

E assim o pequeno Rafael garimpava, com sua pequena máquina fotográfica digital, numa experiência mais vidente que evidente, mais criadora que reprodutora, elementos visuais significantes ou não. Foi desse modo, numa experiência estética reverberada no cotidiano, como uma mediação entre o sujeito e o mundo, que Rafael escreveu e reescreveu com sua pequena máquina fotográfica uma crônica visual sobre os acontecimentos que animavam nosso convívio em Lapinha da Serra.

Os meses que se seguiram reforçam os laços que me uniam a Rafael e a todo o resto de sua família e confirmava a imagem como elo principal dessa união. Passei a restaurar toda a memória visual da família Oliveira, como também realizei um álbum fotográfico de família - antigo dese- jo de seu avô - Seu Juquinha. Um convívio em que o espírito de companheirismo e intimidade se adensava na medida em que mergulhávamos na experiência de partilhar nossas visões de mundo. Relação dialógica que produzia uma curiosa articulação no mais íntimo de cada um de nós, tornando-nos capazes de reconhecer algo do outro em nós mesmos. Bastava que no interior do mundo do outro se esboçasse um gesto que identificássemos como semelhante ao nosso. Rafael me presenteava a cada nova visita que fazia a Lapinha da Serra com arquivos digitais repletos de imagens que captura com sua pequena máquina durante minha ausência, fazendo questão que eu as descarregasse em meu computador. Eram fotos das mais variadas situações e que, pela despretensão com que eram executadas, obrigavam-me, o tempo todo, a experimentar novas formas de leitura e interpretação como meio de acesso àquele universo tão particular. Foram centenas de imagens, fixas e em movimento (seu equipamento registrava também vídeos de pequena duração), que se avolumavam no disco rígido de meu computador, fazendo com que me debruçasse em anotações sobre inúmeras possibilidades de ordená - las - fosse por data, por assunto ou por alguma particularidade. Minhas reflexões ora descreviam círculos cada vez mais amplos, ora cada vez mais estreitos e, invariavelmente, caminhavam rumo a um perfeito vazio. A dúvida me devolvia a indagação: como escolher ou editar esse material? Sob que estatuto me credenciava a imobilizar em pastas e arquivos um conjunto que, no "acaso" da ordem das tomadas, poderia ser lido e relido num percurso sem regras fixas e, a cada nova incursão, revelar outra ordem que não mais a do espaço nem a do tempo, mas a do inconsciente? Só então me dei de conta que mais do que o registro de um estado de coisas, o que sempre me moveu nos momentos parti- 

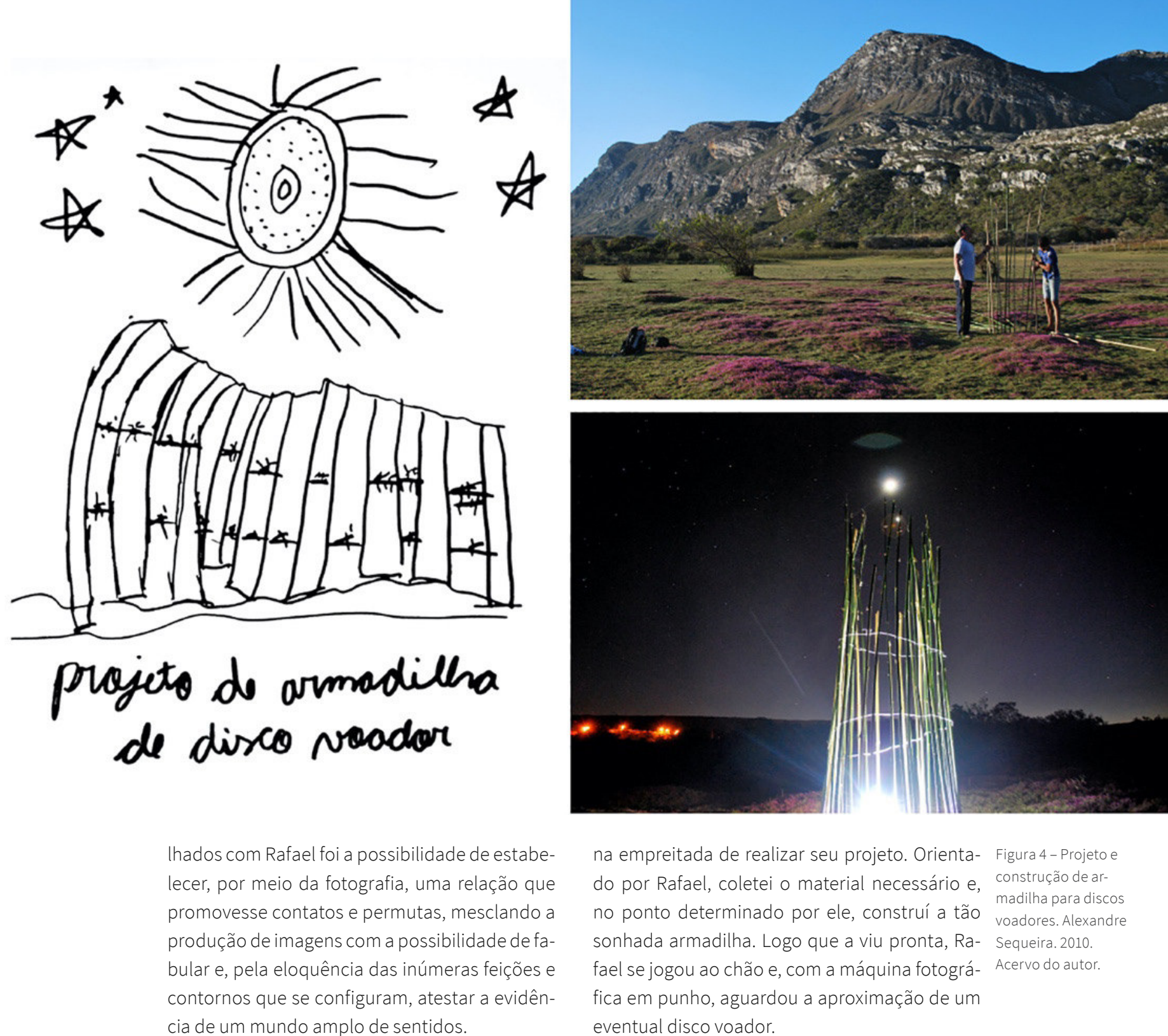

Ihados com Rafael foi a possibilidade de estabelecer, por meio da fotografia, uma relação que promovesse contatos e permutas, mesclando a produção de imagens com a possibilidade de fabular e, pela eloquência das inúmeras feições e contornos que se configuram, atestar a evidência de um mundo amplo de sentidos.

Mas um acontecimento foi determinante para a configuração de uma ação que efetivamente devolveria à vila a fantasia de Rafael revestida de um novo sentido. Rafael voltou ao tema dos discos voadores e me apresentou um projeto para a construção de uma armadilha capaz de capturar os discos voadores que ameaçavam a tranquilidade da vila. Percebi a importância daquela questão para ele e me dispus a ajuda-lo

na empreitada de realizar seu projeto. Orientado por Rafael, coletei o material necessário e, no ponto determinado por ele, construí a tão sonhada armadilha. Logo que a viu pronta, Rafael se jogou ao chão e, com a máquina fotográfica em punho, aguardou a aproximação de um eventual disco voador.

A realização da armadilha de discos voadores definitivamente os laços de companheirismo e confiança que me uniam a Rafael, como também me fez perceber que tudo o que me relatava desde nosso primeiro encontro era uma forma encontrada por um menino sonhador de treze anos para referir-se a efetivas ameaças que sua vila sofria nos últimos tempos e que eu, talvez por uma miopia arrogante comum a mui-
Figura 4 - Projeto e construção de armadilha para discos voadores. Alexandre Sequeira. 2010. Acervo do autor. 
Figura 5 - Postal da Mulher do pé de manga. Alexandre Sequeira.2010. Acervo do autor.

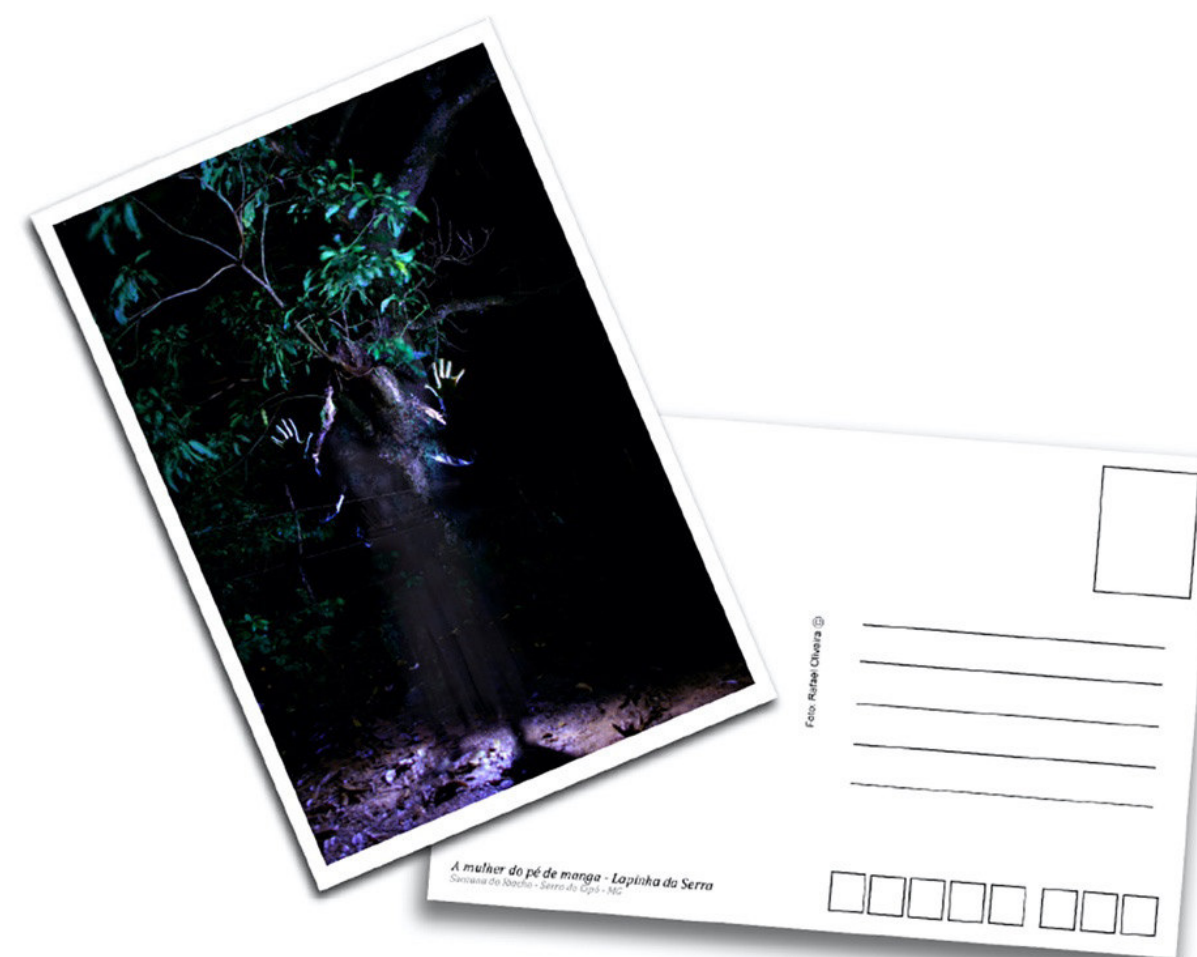

tos adultos, demorei tanto para perceber. Há certo tempo que o asfalto avançava pelas estradas que serpenteiam a Serrado Cipó rumo à Lapinha, trazendo com ele um número crescente de forasteiros com seus veículos barulhentos e seus comportamentos pouco condizentes com os hábitos e valores locais. A presença desses invasores se convertia em ameaça, dado o rastro de lixo e desassossego que deixavam por onde passavam. Sim, Rafael sempre me falou a verdade, só que pela perspectiva de um menino sonhador e apaixonado por seu lugar de origem. Sabia agora que estava diante de um verdadeiro guardião da vila de Lapinha da Serra.

A construção da armadilha para discos voadores fez com que nos lançássemos em uma nova empreitada: realizar uma imagem da tão temida "Mulher do pé de manga", imagem essa que, depois de produzida com o apoio de uma amiga minha que serviu de modelo, retornou à vila na forma de um cartaz com os seguintes dizeres: A Mulher do pé de manga. Quem acredita nela? A ação acabou resultando, para a satisfação de Rafael, no resgate de uma lenda desprezada por quase todos os moradores da vila, mas cultuada solitariamente por ele. A partir da MuIher do pé de Manga, outras imagens produzidas por Rafael retornaram também à vila, agora na forma de cartões postais, ganhando novo valor pelos nativos, na medida em que eram disputados pelos turistas.

Certamente, foi a curiosidade por conhecer um novo lugar, seus moradores, hábitos e costumes

o que inicialmente fez com que me lançasse por caminhos desconhecidos com tão somente algumas indicações e um ponto demarcado em um mapa. Mas foi com o passar do tempo, a par- 
tir de minha permanência e dos contatos que estabeleci, que meu papel pôde ganhar contornos mais definidos. Não havia como se considerar um roteiro prévio; prever como minha estada se daria. Era na disposição ao encontro e à troca que eu poderia vir a ser acolhido e, pelos laços de confiança e afeto construídos, tornar-me amigo. E, assim, na condição de mais um, quem sabe pudesse a partir de meu ofício e junto à Rafael, contribuir na tessitura da delicada rede de valores que sustentam a vida do lugar. Confesso que custei a perceber que as escolhas e ações do pequeno Rafael refletiam, em sua essência, o dilema que a vila de Lapinha da Serra enfrentava. O temor por ele vivido diante da ameaça de um ataque alienígena certamente representava uma projeção infantil das efetivas ameaças vislumbradas com a chegada do progresso. Do mesmo modo, o respeito e importância por ele atribuídos às figuras do imaginário coletivo da vila, como a Mulher do pé de manga, se apresentava como a arma mais potente para a vila fazer frente às trocas simbólicas que se estabeleciam a partir de então com os que chegavam. Questões que dizem respeito às instâncias que sustentam a diversidade de valores que regem a vida do lugar.

Percebo que, a cada novo trabalho que desenvolvo, distancio-me da condição de artista (pontuada aqui segundo o senso comum) para tratar de questões que surgem das relações que estabeleço com as pessoas ou grupos em vivências permeadas por e afeto e confiança. É para o encontro propiciado pela experiência sensível do viver que dirijo minhas atenções, para dela redefinir minha prática não apenas no campo das artes, mas também no campo da educação. E assim, cada nova experiência aponta para um horizonte de novas questões que só o desenrolar da ação é capaz de elucidar. São práticas que têm assumido, cada vez mais, uma confor- mação final de espaços de narrativa, como estímulo imaginativo suficientemente capaz de, através de palavras e/ou imagens compartilhadas, conduzir o outro a um espaço de imanência - território de subjetivações capaz de recriar o momento vivido e assim potencializar outras novas vivências. Descrever um acontecimento ou um encontro é a melhor forma de prestigiá-lo, imprimindo-lhe nuances talvez ocultas no instante em que ocorreu, reforçando, assim, o privilégio de haverem existido. Mas, já que efetuar registros concretos não se constitui um hábito cotidiano, uma vez que poucas pessoas vivem a vida atentas a preservá-los, busco registrar na memória alguns momentos. Não tenho a pretensão de uma averbação do que efetivamente aconteceu, mas sim de somar personagens e fatos ao meu repertório particular, reunindo pequenos gestos, olhares e palavras numa trama alegórica, para que possa, num momento futuro como este, reconvocá-los, em diferentes graus e matizes, na crônica de minha vida. Tessitura que se faz da escolha e edição de fragmentos de momentos significativos vividos. Momentos como esses que divido com vocês aqui, e que me fazem almejar um sentido de documento capaz de acolher tantas formas de interpretação do real quantas possíveis. Documentos (sejam eles visuais ou não) que reconheçam, por exemplo, o direito a existência de discos voadores ou da Mulher do Pé de Manga.

\section{Referências}

ANDRADE, Rosane. Fotografia e Antropologia. Olhares fora-dentro. São Paulo: Estação Liberdade/EDUC, 2002.

BISHOP, Claire (Org.). Participation. Documents of Contemporary Art. London: Whitechapel, 2006.

BOURRIAUD, Nicolas. Pós-Produção. Como a Arte reprograma o mundo contemporâneo. 
São Paulo: Martins Fontes, 2009.

BOURRIAUD, Nicolas. Estética Relacional.

São Paulo: Martins Fontes, 2009.

CANCLINI, Nestor Garcia. A globalização imaginada. São Paulo: Iluminuras, 2007.

COUTINHO, Evaldo. A Testemunha Participante. São Paulo: Perspectiva, 1983

DIAS, Rosa. Nietzsche, vida como obra de arte. Rio de Janeiro: Civilização Brasileira, 2011.

EDLES, Laura Desfor. Cultural sociology in practice. 21th. London: John Wiley, 1991. (Century Sociology collection)

HUIZINGA, Johan. Homo Ludens. São Paulo: Perspectiva, 2001.

MATURANA, Humberto. Emoções e Linguagem na Educação e na Política. Belo Horizonte: Ed. UFMG, 2005.

SHUSTERMAN, Richard. Vivendo a Arte. São Paulo: Editora 34, 1998.

ZOLADZ, Rosza W. Vel. (Org.). Imaginário brasileiro e zonas periféricas. Algumas proposições da sociologia da Arte. Rio de Janeiro: 7Letras/Faperj, 2005.

\section{Alexandre Romariz Sequeira}

Artista visual e pesquisador, é Doutor em Arte pela UFMG e professor da Faculdade de Artes Visuais/Instituto de Ciências da Arte da UFPa. Desenvolve trabalhos que estabelecem relações entre fotografia e alteridade social, tendo participado Encontros de Fotografia, Seminários e Exposições no Brasil e exterior. Tem obras no acervo do Museu da UFPa, Espaço Cultural Casa das 11 Janelas; Coleção Pirelli/MASP, Museu de Arte do Rio/MAR, Museu de Arte Contemporânea do Rio Grande do Sul, Museu da Fotografia/ CE, Coleção de Fotografia da Associação Brasileira de Arte Contemporânea/ABAC. 